\title{
Participation in Design Things
}

\author{
Pelle Ehn \\ School of Arts and Communication \\ Malmö University \\ SE-205 06 Malmö Sweden \\ pelle.ehn@mah.se
}

\begin{abstract}
This paper discusses the design of things. This is done in an attempt to conceptually explore some of the political and practical challenges to participatory design today. Which things, and which participants? The perspective is strategic and conceptual. Two approaches are in focus, participatory design (designing for use before use) and meta-design (designing for design after design). With this framing the challenge for professional design to participate in public controversial things is considered.
\end{abstract}

\section{Keywords}

Design, thing, object, participation, use, public.

\section{THINGS AND OBJECTS}

People are fundamental to design, but also objects and things. But what do we mean with objects and things in design? In this paper the starting point is the kind of sociomaterial assemblies that Bruno Latour so strikingly has characterized as 'collectives of humans and non-humans' [33]. An early form of this collective was the Thing, and this thing was originally both social and material. In preChristian Nordic and Germanic societies these things were the governing assemblies and places, where disputes were solved and political decisions made. Participatory design, as it emerged in the 1970's in Scandinavia, may theoretically and practically be seen as contemporary examples of such things or rather 'thinging' (as Heidegger would call it). Latour has in this spirit recently called for 'thing philosophy' or 'object oriented politics' [34]. His explicit references to object oriented programming is partly puzzling, but in our context also highly interesting, not least since a key actor in the early making of participatory design in Scandinavia, Kristen Nygaard, also was one of the inventors of object oriented programming. Here, however, focus will be on the design thing and on strategies for making this thing public, rather than on software architecture. This includes the object of concern in design, the design object and its many 'representatives', the design of things as matters of concerns and possibilities of experiences. So design things are in focus when inquiring into the 'agency' of not only designers and users, but also of non-human 'actants' such as objects, artifacts and design devices. How do they get things done their way? The perspective is one of participation, intervention and performance of, and in, this thing. How is design and use related? Who to design for and with? Where, when and with what means? How does a design project and design processes align human and non-human resources to move the object of design forward, to support the emergence, translation and performance of this object? How may designers participate in these things and position themselves in the 'collectives of humans and non-humans'.

As the paper evolves two complementary positions and strategies will be explored: participatory design and metadesign. Participatory design is characterized as an approach to involve users in the design and, as suggested by Redström [45], in the design process encounter 'use-beforeuse'. Participatory design is seen as a way to meet the unattainable design challenge of fully anticipating, or envisioning, use before actual use, takes place in people's life-worlds. The latter strategic position, meta-design, suggests to defer some design and participation until after the design project, and open up for use as design, design at use time or 'design-after-design' [45]. Meta-design is explored as a way to meet the equally unachievable design challenge of all-encompassing anticipation or envisioning of potential design to take place in use after project design.

To deal with these challenges, a more general understanding of design processes as entangled culturalmaterial design-games will be elaborated in the paper. This design-game concept for exploring design processes is worked out on the basis of concepts of participation, communication, community, language and artifacts. In these design-games special attention will be paid to 'representatives' of the design object in the material form of prototypes and models, acting as boundary objects [47], aligning participants in synchronous design-games of designers and users (participatory design), as well as on infrastructures and the process of infrastructuring [48] binding design-games of designers and future designers/users together (meta-design). In both design approaches things modifying the space of interactions (e.g. boundary objects in participatory design and infrastructures in meta-design) will be explored as socio-material frames for controversies, ready for unexpected use, opening up 
new ways of thinking and behaving. The paper ends with some reflections about thing politics and the future of participatory design and designers participating in public controversial things outside the boundaries of the safe design project. So in terms of participation the paper deals not only with the participation of users and designers in design projects, but also with the participation of material 'non-humans', and of people and their usage unknown to the designer at project time.

\section{DESIGN PROJECT THINGS}

But first a note on the design project, the kind of sociomaterial thing that is the major form of alignment of design activities and what in this paper will be called designgames. A project is the common form for aligning resources (people and technology) in all larger design endeavors. Projects are things that have objectives, time lines, deliverables, etc. In practice, resources to align in a participatory design project may for example include: project brief; prototypes; cultural probes; sketches; ethnographies and other field material; buildings; devices; project reports; 'users'; engineers; architects; designers; researchers; other stakeholders; etc.

The outcome of a design project is both a device and a thing. From what we may call an engineering perspective, it can be seen a device, the embodiment of the object of design, providing users with access to some functions (a chair for sitting, a cellular phone for making telephone calls, exchanging messages, etc). But from a social and architectural perspective, the chair or the cellular phone as outcome of the design process is always a thing modifying the space of interaction for its users, ready for unexpected use, rich in aesthetic and cultural values, opening up for new ways of thinking and behaving.

Often a project is designed to go through a number of consecutive stages of gradual refinement. They typically have names like 'analysis', 'design', 'construction' and 'implementation'. However, the shortcomings of such an approach are well known and many: a top-down perspective hindering adaptation to changing conditions, hierarchical construing legitimate participation, the rigidity of specifications, etc. Hence, the call for user involvement and participatory design approaches.

So rather than thinking of a project as a design thing in terms of phases of analysis, design, construction and implementation, a participatory approach to this collective of humans and non-humans might rather look for the performative 'staging' of it. Inspired by Pedersen [44] we could then ask: How to construct the initial object of design for the project? That is, how to align the participants around a shared, though problematic, object of concern? As work proceeds, how can the involved practices be made reportable (fieldwork, ethnographies, direct participation, etc)? How can the object of design be made manipulatable. That is how are 'representatives' of this object enrolled in forms that can be experienced (sketches, models, prototypes, games, etc)? How is the object of design made into a public thing and open to controversies among participants in the project as well as outside (workshops, exhibitions, public debate, etc)?

Projects are however, as Krippendorff [29] has pointed out, only part of, or a specific form of, alignments in the life cycle of a device, and every object of design eventually has to become part of already existing ecologies of devices (in peoples already ongoing life-worlds), be they digital like computer applications and databases or physical like buildings, furniture, doors, books, tools, vehicles, etc. Hence, the beginning and end of a designed device is open, and hardly ever constrained to the limits of the project. This is principally interesting because it points at the importance of understanding how design in a project is related to users/stakeholder appreciation and appropriation, be it as adoption or redesign, and how users make it part of their life-worlds and evolving ecologies of devices. Design might be thought of as constrained to a specific project with given objects of design, resources, timelines and specified outcomes, but since the final embodiment of the object of design is a thing, this thing opens up for unforeseen appropriation in use in already existing, evolving ecologies of devices.

Hence, strategies and tactics of design for use must also be open for appropriation or appreciation in use, after a project is finished, and consider this appropriation as a potential, specific kind of design. In fact Krippendorff's notion also implies that in design for use we also should focus on the 'before' the project, the 'procurement' process of aligning actants in a design project and how objects of concern becomes a specific object of design. This may involve making explicit the often hidden performative "protocols of design' initially setting the stage for design-games establishing the object of design $[10,44]$.

For now, however, we narrow the focus to the design project, to the relation between design and use in this sociomaterial thing as participatory design and as meta-design.

\section{PARTICIPATORY DESIGN: DESIGN FOR USE BEFORE USE}

\section{Participatory design as empowerment}

Designers approach to use has dramatically changed over the years. From total focus on the artifacts designed and their functions, on usability, via different ways of testing users, studying use and involving potential users in the design process. Examples of approaches range from usercentred design focusing use and usability see e.g [43], contextual design focusing on the situatedness of use see e.g. [4], to contemporary approaches of experience design focusing on creating experience for the user see e.g [46]. Participatory design, which is in focus here, exists in this design context with a special focus on people participating in the design process as co-designers. As mentioned we could say that all these approaches try to meet the challenge of anticipating, or at least envisoning, and designing for use before it actually has taken place - design for use before use [45]. 
Participatory design has its roots in movements towards democratization at work in the Scandinavian countries. In the 1970s participation and joint decision-making became important factors in relation to work places and the introduction of new technology. Participatory design started from the simple standpoint that those affected by a design should have a say in the design process. This was a political conviction not expecting consensus, but also controversies and conflicts around an emerging design object. Hence, participatory design sided with resource weak stakeholders (typically local trade unions), and developed project strategies for their effective and legitimate participation.

A complementary reason for participation, and in the long run probably the strongest motivation for its use in many organizations, was to ensure that existing skills could be made a resource in the design process.

In summary, one might say that two types of values strategically guide participatory design. One is the social and rational idea of democracy as a value that leads to considerations of conditions for proper and legitimate user participation. The other value might be described as the importance of making the participants 'tacit knowledge' come into play in the design process, not only their formal and explicit competence. For a background and overview see e.g. $[15,22]$.

\section{Participatory design as entangled design-games}

Early attempts to conceptualize participatory design as a pragmatic design theory were done through reference to Wittgenstein and the language-game philosophy. Design was seen as meaningful participation in intertwined language-games of design and use (professional designers and professional users), where 'performative' design artifacts such as prototypes and 'design games' could act as representative 'boundery objects' binding the different language-games together $[54,15,47]$. So the suggestion was to regard the design process as a set of such intertwined language-games of design.

From this followed the specific design challenge to set the stage for yet another specific design language-game that has a family resemblance with (professional) languagegames of different stakeholders, especially users (laydesigners) and (professional) designers. In the language of this paper, this meant literally constructing a socio-material design thing, a meaningful potentially controversial assembly, for and with the participants in a project.

This led to recommendations and practices where the basis for the design process became the (work) practices of legitimate but resource-weak stakeholders (actual or potential 'end-users'). Work ethnographies and other ways to focus on the users understanding became basic. So did engaging and participative design activities like participative future workshops [28]. But most significant was the replacement of 'systems descriptions' with engaging 'hands on' design devices like mock-ups and prototypes and organizational games that helped maintain a family resemblance with the users everyday practice, and supported creative skilful participation and performance in the design process. There was a decisive shift in design methods towards user participation as 'design-by-doing' and 'design-by-playing' [16,17].

In retrospect, this understanding of participatory design, and the recommendations, still appear to be valid, though some complementary conceptualizations may prove useful. For example there are interesting connections between notions of participation in language-games and John Dewey-inspired pragmatism: how 'communication is to take part in a community'; how 'design-by-doing' and 'design-by-playing' relate to 'learning-by-doing' as fundamental forms of inquiry.

One specific conceptual framework in this pragmatic tradition is the focus on collective, cultural-historical forms of located, interested, conflictual and meaningful activities in 'communities-of-practice' as developed by Jean Lave and Etienne Wenger [36, 53]. Communities-of-practice resembles language-games as elaborated above, but the concept is broader and has its point of departure in everyday practice of professional communities. We can say that many specific language-games are carried out in a community-of-practice. In communities-of-practice there is a strong focus on 'learning' as the act of becoming a legitimate participant, establishing relations to other 'older' participants and learning to master tools and other material devices. Compared to language-games, focus is not on language as practice, but on practice, with participation as the fundamental epistemology, where participation is understood as the "complex process that combines doing, talking, thinking, feeling, and belonging. It involves our whole person including our bodies, minds, emotions, and social relations" [53, p. 56].

When thinking in terms of communities-of-practice in a framework for participatory design, a dimension of internal power struggle becomes apparent, in the attempts by participants to appropriate devices and social relations. Hence, the understanding of things as socio-material controversial events in the life of a community-of-practice (or across different communities-of-practice) is underlined, as is their central role in creating alignments.

With this conceptualization, it also becomes more clear that human action and participation is 'stretched over, not divided among' the physical, social, and cultural contexts in which it emerges [35]. A further important gain from a design perspective is the attention drawn to appropriation of design devices (and their agency), rather than just 'languaging'. Fundamentally there is, as Wenger has underlined, an important dialectic and close relation in communities-of-practice between participation and materialization (reification), the enrolled 'representatives'. They reciprocally form each other. Through participation in the process of reification, "giving form to our experience by producing objects that congeal this experience into thingness" [53, p.58), design devices (and future objects of 
use) are from the beginning vested with meaning. Reifications are 'always incomplete, ongoing potentially enriching, and potentially misleading'. Hence participation overcomes some of the limitations of reification. Reifications means enrollment of 'representatives' of the object of design in the design process. This 'means temporarily hardening or solidifying of experience which negotiations are organized around'. Use then means, as Björgvinsson has called it, 'defrosting' these reifications through participation in future use [5].

Hence, it would be possible to conceptualize participatory design, in a parallel way as was done based on languagegames, as overlapping communities-of-practice (users as legitimate peripheral participants in design and vice versa designers as legitimate peripheral participants in use) This is also in line with the idea of understanding the design process as the meeting between communities-of-interest [19].

As a notion of design practices that recognize both the semantic and the pragmatic aspect, the suggestion in this paper is to see design as participative, entangled, meaningmaking design-games (having a conceptual family resemblance both with intertwined language-games and with overlapping communities-of-practice).

Hence, participatory design can be seen as a process of entanglement of many different design-games, for example:

- There are the many everyday professional (design)-games of both users and designers (participants everyday practice related to a design project understood as design-games).

- There are the explicitly constructed specific design-games that have family resemblance with these everyday designgames (the design process as a shared design thing).

- There are specific performative 'design-by-doing' and 'design-by-playing' design-games (design methods and devices understood as design-games).

- Though not design-games in the same sense, there are even specific 'design games' like participatory organizational games [17], 'concept design games' [24] or 'video as design material' [8] (the use of specific design devices understood as design-games).

Non-human design participants and representatives

Before leaving participation and design for use, let us in some more detail reflect upon non-human participants and the role of design devices and artifacts (e.g. prototypes, mock-ups, design games, models, sketches and other materials) in intertwined design-games in a design.

In project work there is a strong focus on 'representations' of the object of design. Traditionally they are thought of as gradually more refined 'descriptions' of the designed object to be. The suggestion here is instead a focus on these devices as on the one hand material 'representatives' of the evolving object of design, and at the same time sociomaterial public things, supporting communication or participation across design-games in the design process.
They are potentially binding different stakeholders together, and there is clearly also a performative dimension of the evolving object. These 'representatives' of the object of design have of course to be elected and enrolled by the other participants, but, once engaged, they are active participants in the design thing as a collective of humans and non-humans.

We may also view design devices (at the same time 'representatives' of the design object and public things) as 'boundary objects', with a conceptualization borrowed from Susan Leigh Star [49]. The meaning inscribed in design devices, like a model, makes them meaningful in different intertwined design-games. At the same time, they may be invested with lots of meaning to professional designers and to users respectively, meaning that is not shared across their respective professional design-games. Boundary objects might be weakly structured as to achieve flexibility and allowing transference and commonality, but strong enough to be used in individual use or use in a uniform environment. They are reifications intrinsically bound to overlapping design-games, hardened to stabilize meaning but also to be 'defrosted' in recurrent use.

Hence, in any design process it would be important, when establishing things as shared design-games, to consider how such boundary objects can be identified and enrolled, and at the same time be aware of the diverse meanings that these 'representatives' may carry in relation to the different design-games at play.

We can also, as Kathryn Henderson [25], in her study of engineers' use of design devices, regard these 'representatives' as 'conscription devices', focusing on their use in overlapping design-games as pointing to other devices to be designed. Hence, their role becomes not only one of being meaningful to all participants, but also one of aligning meanings of the evolving object of design by suggesting directions for new 'representatives' and for signifying potential transformations as next moves in ongoing design-games.

With this view on participatory design and design for use as participative entangled meaning making design-games and design devices as 'representatives' for the evolving object of design and at the same time public things for binding these design-games together we will now look into challenges to this participative approach.

\section{META-DESIGN: DESIGN FOR DESIGN AFTER DESIGN Meta-design and infrastructuring}

One limitation of participatory design as conceptualized above is the focus on projects supporting identifiable users. Basically, the design process described is laid out to support such users' interests, and the products or services designed to be supportive of this. As critics have accurately pointed out, there are stakeholders other than immediate users, and people (both immediate and future users) will appreciate and appropriate designed devices in totally unforeseen ways. Envisioned use is hardly the same as actual use, no matter how much participation there has been 
in the design process. Does this mean that the idea of participatory design and the envisioning of 'use before use' have to be given up altogether?

The most common reply to this challenge to participatory design has been ideas of flexibility in use or open systems, designing devices for tailorability, making it possible for user to appropriate devices in use by for example customizing and extending them according to the varying skills and needs [40]. A similar approach has been the idea of a continuing design-in-use [26]. In a broader design perspective, this also corresponds to visions and notions like continuous design and redesign [27] and unfinished design [51]. In such approaches there is a strong focus on how users appropriate a given technology. Here we are particularly interested in what designers do and how this relate to unforeseen users' appreciation and appropriation of the object of design into their life-worlds.

Whereas the use of cultural probes (like disposal cameras and post cards) essentially has been a new way to make it possible for designers to share specific, situated user experiences as inspiration for the design work [21], what we are looking for here is in a way the opposite. How can users in their design-games be inspired by and 'enact' the traces, obstacles, objects and things left by the professional designers? What we are searching for is a kind of design after design. Design-games different from those played by professional designers and users in a project, but nevertheless design-games (in use). This is not to suggest that all appropriation in use can or should be understood as design, but only to open up for design approaches in design projects supporting this kind of appropriation.

One approach in this direction is meta-design. Here both professional designers and potential users are seen as designers, much as in participatory design, but they are not participating in synchronous entangled design-games, but in design-games separated in time and space. Such a metadesign approach has been described by Fischer and Scharff [18] and Fisher and Giaccardi [19] with reference to earlier work both in art (e.g. by Gene Youngblood and Derrick de Kerchove) and in theory of knowledge and biotechnical design (e.g. by Paul Virilio and Umberto Maturana). Rather than focusing on involving users in the design process, focus shifts towards seeing every use situation as a potential design situation. So there is design during a project ('at project time'), but there is also design in use ('at use time'). There is design (in use) after design (in the design project

This has a number of strategic consequences in relation to design for use in general, and not least for participatory design. In design-games carried out at project time, it has to be acknowledged that there are design-games that go on as users play along in use, and eventually also design-games with entirely new stakeholders. As a consequence it becomes crucial in the design-games at project time to support design-in-use, design-games at use time. Hence, there will be a shift in focus from design-games aiming at useful products and services, to design-games to create good environments for design-games at use time. Typically this will at project time lead to an occupation with identifying, designing and supporting social, technical and spatial infrastructures that are configurable and potentially supportive of future design-games in everyday use.

Shifting from design for use to design-for-design, we seem to be confronted not only with intertwined design-games, but also a chain of one design-game after another. As in participatory design, the designed devices are both 'representatives' of the objects of design and, as boundary objects, also socio-material public things. However, the objects of design in design projects and in use are different. At project time the object of design is to produce a public thing open for controversies from which new objects of design can emerge in use.

It is this mediation Leigh Star has called 'infrastructuring', and it is more a 'when' than a 'what' [48, 49]. An infrastructure, like railroad tracks or the Internet is not reinvented every time, but is 'sunk into' other sociomaterial structures and only accessible by membership in a specific community-of-practice. Infrastructure or rather infrastructuring is a socio-material public thing, it is relational and becomes infrastructure in relation to designgames at project time and (multiple potentially conflictious) design-games in use. The challenge and object of design for professional design at project time is the design of such potential public things that as infrastructuring can become objects of design in use. But who the participants in this public thing will be, and the way they may appropriate it, must be partly left open.

\section{Infrastructuring strategies}

With this positioning let us explore a few potential metadesign strategies to be enacted as design at project time, supporting the flexibility, openness and configurability of infrastructures as socio-material public things in designgames at use time.

From a technical point of departure, obviously such infrastructuring strategies could focus on the design and negotiation of 'protocols' and 'formats', on 'protocolling' and 'formatting'. Only think of Internet communication protocols like TCP/IP, HTTP and FTP, which have been essential to the success of the net. But this 'protocolling' could also be understood more socially and developed as in diplomacy for governing relations in the making of procedural agreements. From the digital domain one could also think of inspiration from the making of file format conventions like ASCII, HTML and JPEG. But maybe more interesting is the making and use of 'formats' in architecture. Here formats are principal solutions with clear characteristics like the 'basilica'. But the format has some elasticity that makes it open to context, change and adaptability, to deliberate transcending without being distorted.

More general strategies to create infrastructures that are flexible and open for design after design and unforeseen 
appropriation has to do with providing means for configuring. There are at least two types of configuring design-games played in use: adapting a space to a diversity of uses and identities, and configurations of devices within the physical space.

However, how possibilities for configurations of space are being appropriated in configuring design-games that occur in a specific practice are not a priori given. Designers might at project time, when forming the infrastructure, have certain games in mind, but which ones that are really played out is determined in actual use and that might be very different from the design-games envisioned.

A component strategy is a specific strategy for connecting design-games at project time with design-games at use time, based on the idea of building a configurable 'infrastructure' working with general building blocks, components and component assemblies. This is a kind of engineering or 'LEGO block' approach. Exemplary prototypes may be seen as 'boundary objects' between the design-games of a design team and those of the 'designing users', boundary objects to be configured and appropriated by the users.

This configurability may be directly supported by software platforms. A good example is the open source PALCOM architecture with support for 'assemblability' (of components) and 'inspectability' (of assemblies of infrastructure and components). But infrasructuring can never be reduced to the technical platform [8]. Infrastructuring can never be de-contextualized, even if the context is unclear from the beginning.

Rather than designing a technical platform ("thin infrastructure') design at project time as infrastructuring may, as argued by Baker, be concerned with 'thick infrastructure' [2], with the mutual constitution of the social and the technical and the heterogeneity of potential design-games.

And even when focusing 'thin infrastructure', on technical platforms and middleware software, supporting appropriation and use of different devices, it seems that involving users in design and evaluation is a fundamental strategy for success [14].

Another infrastructuring strategy may be the development of design patterns. The idea originates from the renowned work of architect Christopher Alexander in the 1970s on a pattern language. It may be seen as an alternative configuring approach, maybe more architectural than engineering in its orientation. Alexander and his colleagues aimed at identifying and articulating certain spatial configurations in buildings and towns. Such configurations they called patterns [1]. Patterns are documented in terms of context of use, problematic situation, and proposed solution. Design patterns are, in the pattern language by Alexander, systematically related to one another. More important in our context of meta-design and entangled design-games is the suggestion that the work of articulating and refining patterns should be understood as a way to reconnect to traditions of local planning, supporting user participation in planning and appropriation of their own environment.

Patterns and pattern languages have later been adopted by for example both the software engineering community and by human computer interaction researchers and practitioners [5]. Other patterns include patterns based on ethnographic observations supporting interactive design in domestic settings [12] or the generative design abstractions for pervasive computing products [40]. The important aspect of patterns as seen as aspects of an infrastructuring strategy is the focus on their support for appropriation in use, as vehicles for design in use.

Yet another perspective on the 'infrastructure' as a relation between design at project time and design at use time is domain-specific languages or environments. Especially ontologies have for some time attracted much attention in relation to design of knowledge based systems and in relation to specific domains. Typically an ontology is like a dictionary or glossary, but with a structure that enables a computer to process its content. An ontology consists of concepts and relations that describe a certain domain within for example architecture or engineering. See e.g. [18].

Ontologies are great for exploring complex domains, so, in a sense, it seems as a reasonable infrastructuring design strategy to develop them at project time, at least if they are open and potentially evolving in use. But where do they come from and how do they become appropriated in design-games at use time? Any attempt to build a universal ontology comes in conflict with the evoultion of the object of design in specific localized design-games.

The ontology is not a conceptual map of the world as it is, but a boundary object among many in an infrastructure, maybe even a public thing intertwining design-games at project time with those played in use. Ontologies, it seems, have not only to be situated, but also continuously negotiated as we play along. They must be open, controversial things.

This brings us to a reverse infrastructuring strategy. What would an 'infrastructure' be like that is not total or universal, but that is taking all kinds of existing, modified and future artifacts and devices in a specific domain into account? The idea of an 'ecology of devices' as suggested by Klaus Krippendorff (based on notions by Gregory Bateson and Kenneth Boulding) is one such approach [29]. Generally, ecologies are about how large numbers of plants and animals interact by feeding on each other, reproducing, finding a niche (or becoming extinct), etc. Typically ecologists study ecosystems in specific and particular domains such as lakes or forests.

Though most of us know more 'species' of devices and artifacts than species of living organisms, less attention has been paid to ecologies of devices where e.g. windows, tables, chairs, lamps, doors, computers, displays, books, 
images, models, bags, tools, shirts and shoes interact in an environment. Of course, a main difference between ecologies of living organisms and ecologies of devices is that whereas biological species interact on their own term any ecology of devices is performed by people using these devices.

What Krippendorff proposes is that in an ecology of devices the meaning of a device consists of its possible interaction with other devices, and that no device can be realized within an ecology without being meaningful to those who can 'move' it on. Hence the proposition is, in analogy with biological ecologies, but with a focus on meaning, to explore 'cooperation', 'competition', 'interdependence', 'reproduction' and 'retirement (death)' of devices in specific cultures, or we might say communities-of-practice or even design-games. With such an approach to infrasructuring and the coupling of designgames at project time and design-games at use time, a design team would pay considerable attention to understanding the ecology of devices in the practice they are designing towards. This would not be all too different from the kind of ethnographic and historical accounts made in many participatory design projects today, but the attention would be different, since the ecological preunderstanding of the devices in play, for good and for bad, would dominate. But maybe more important, 'protocols', 'formats', 'components', 'patterns' and 'ontologies' or other suggested boundary objects, conscription devices or infrastructures would have to be seen in the perspective of their contribution to the design-games played in already existing ecologies of devices. How will users make these devices compete and cooperate today and tomorrow? Will they find a proper place and role for the new suggested 'representatives' of the object of design in their designgames?

Design answers to such questions must by necessity be humble. Maybe we can say that in this strategy one must at projects time try to develop the very object of design as a public thing which potentially by the meaning making of its users can make its way into their life-worlds and already existing ecology of devices. But the questions are not questions of design from nowhere. The answers are also a matter of how designers engage in strategies to make their designs advantageous among stakeholders giving meaning to specific ecologies of devices.

Hence, strategies of participatory design, engaging potential future users, are not contrary to meta-design and infrastructuring, but may despite the uncertainties of who will be the future users and how they will appropriate infrastructures and new devices be a most advantageous strategy also when infrastructuring.

\section{PARTICIPATION AND CONTROVERSIAL THINGS}

The challenge from social software

In the early development of the perspective of participatory design a new role for the designer at project time in setting the stage for shared design-games, of shaping a design thing, was envisioned. In this paper this role has been further elaborated, focusing on infrastructuring of public things, supporting future appreciation and appropriation as an activity of design at use time. However, there may also be a new role for the professional designer and future design-games taking place out of the design project context. This paper ends with some reflections about such future design-games.

Social software and Web 2.0 infrastructures like YouTube, MySpace, Facebook and Flicr have now for some years been extremely successful as platforms for massive participation in creating and sharing popular cultural material across small and large, homogeneous and heterogeneous communities and places. In a discussion about participation in design things such phenomena cannot be ignored. What roles could and should professional design play in creating such infrastructures and things and making them public? Is actual design in use all that matter here?

Public infrastructures maybe more relevant as challenges to design and participation are open applications, infrastructures and communities like open source, Wikipedia, and creative commons. Wikipedia is growing as a gigantic, participative open resource for creating, sharing and negotiating knowledge. 'Creative commons' as infrastructure helps open sharing of creative content and intellectual property across design-games rather than privatizing creativity and locking it into patents. Open source movement is in many ways the generic pattern for such communities and their design-games, including the risk of turning into a too rigid infrastructure for really creative design. However these design strategies do not have to be restricted to the digital territory. A thought provoking example is 'free beer' by performance artist group SUPERFLEX. 'Free beer' is not given away, but it is an open source beer. The recipe is openly available under a creative commons agreement with free rights to use and improve the design, provided that the improvements are shared and due credits given.

Strategies for massive participation in design and designin-use are also developed in other fields. One example is the influential Massive Change approach as suggested by Bruce Mau [39], placing design as a major participative practice shaping our world. Another famed bottom-up and collective participative design approach is 'pro-am' and 'we-think' as for engaged professional amateurism outside the established economies in developing social software for social change, participative public services, etc [36]. And in an even wider perspective, participative strategies for innovative design and the formation of infrastructures in which people can express themselve creatively, and collaboratively engage in meaningful activities and designgames [55]. And then, maybe in the other end of the spectrum and in the age of new media, there is the revival of the DIY (do-it-yourself) tradition emanating from the punk generation, not least in communities of young game 
players, in the "machinima" tradition, turning off the shelf game machines into their own advanced amateur media production tools.

What is the role of the professional designer in this kind of design-after-design as an application of the 'ready-made' strategy of re-contextualization and re-appropriation, once practiced by Duchamp in the artistic filed, but now deliberately and skillfully practiced by 'misusers' as an everyday new media design strategy?

Furthermore, how does the professional designer position herself given the paradoxical situation that Web 2.0, social software applications and massive user participation in creative production seem to be not only an 'alternative' more 'democratic' mode of production, but also a major feature in the self image of the contemporary business world?

Toward this background, it seems relevant to return to the objectives of participatory design and recast them in the perspective of design-for-design and potential massive participation as design in use.

\section{Accountability and infrastructuring}

Participatory design once grow out of a concern about how design could support resource-weak groups when information technology was introduced to the workplace. It also meant a clear positioning of the designer in controversies regarding how the design was implemented in use.

Democracy and skill as guiding values for participatory design lead to an interest in supporting legitimate participation as well as possibilities for users to express and communicate 'tacit knowledge' and "aesthetic experience".

Continuing participatory design into design-for-design and design-in-use the same guiding values, once advocated to counter a hierarchical and formalistic design process characterized by dominance, may prove useful. Dominance, hierarchy and formalisms are certainly ways in which many social, technical and spatial infrastructures can be characterized. Hence the rational idea of democracy and legitimate participation may, in design-for-design, lead to a focus on infrastructuring in support for communication and community building free of coercion at use time. But we must then as Star [48] points out pay special attention to those 'marginalized by standardized networks' or infrastructures. This cannot, however, be perused and performed in any universal sense as 'design from nowhere', but only as expressed by Haraway as "politics and epistemologies of location, positioning and situating, where partiality and not universality is the condition of being heard to make rational knowledge claims" (23, p. 195), and as suggested by Suchman as 'located accountability' [50]. In this perspective, design as 'democratic innovation' becomes a question, not so much about the 'new' or about patents, but more about, as Barry suggests, everyday practice in particular sites and locations committed to the work of envisioning emerging landscapes of design through which social and material transformations take place as 'opening up' of questions and possibilities [3].

\section{The public and controversial things}

Years ago Berard Tschumi suggested such strategies for opening up controversial things as a kind of 'event architecture' where the focus is on designing 'architectureevents' rather than 'architecture-objects' [52]. Here the infrastructure supports multiple and heterogeneous, often controversial, design-games in use (rather than homogenous and unitary ones). This infrastructuring may for example be achieved by explicit programming tactics exploring disjunctions between expected form and expected use like in cross-programming (e.g. suggesting using a church building for bowling).

A recent social software example is how Facebook in 2007 was appropriated for a kind of 'open source politics'. Amateur activists and major political nonprofit groups appropriated it as a powerful infrastructure for organizing worldwide protests against Mynamar's violent attack on the monk's pro-democracy demonstrations.

A more far-reaching example in terms of finding ways to 'redesign' existing technology and infrastructure and turn it into a controversial thing is 'The French Democracy', as analyzed in Lowood [38]. The background was the riots in a largely African Arab Parisian suburb in November 2005 triggered by the electrocution of two teenagers fleeing from the police. At about the same time a computer game, a Hollywood studio simulation and a toolbox for making animated movies for that studio, was released. The game player community, however, quickly found ways to tweak the game into a production tool for making independent animated movies. One of them was a freelance industrial designer with no experience in making movies. Under the name of Koulamata he in a few weeks produced and made public 'The French Democracy' [30] as short stories commenting upon the victimization of minority groups through harassments and job discrimination and the state of French historical ideals of liberty and fraternity. 'The French Democracy' was massively downloaded from the Internet and commented upon in several online forums and soon also was taken up in the public debate in a broad spectrum of mainstream media.

This DIY approach of finding technology and by creative 'misuse' transforming it into new design devices, to new acting 'representatives' is certainly also a challenge for professional design. As is the way communities of young people can turn their game environments into tools for public discourse on public events. What is the role of professional design in such controversial things, extending design into political processes, public debates and subversive but creative misuse?

In this paper, on participation in design things, the philosophical pragmatism of John Dewey and the 'thing politics' of Bruno Latour [34] has been corner stones for reflecting upon design as participation in collectives of humans and non-humans and how we 'live in 
communication'. Dewey's position on controversial things and the public makes design even more challenging. He argued $[13,41]$ that in fact the public is characterized by heterogeneity and conflict. It maybe challenging enough to design for, by and with communities-of-practice in entangled design-games where common social objectives are already established, institutionalized or at least within reasonable reach. Social communities supported by relatively stable infrastructures. But the really demanding challenge is to design where no such consensus seems to be within immediate reach, where no social community exists. In short, where a political community, a public characterized by heterogeneity and difference with no shared object of design, is in need of a platform or infrastructure. Not necessary to solve conflict, but to constructively deal with disagreements - public controversial things where heterogeneous design-games can unfold and actors engage in alignments of their conflicting objects of design. Participation in the making of such things stands out as the ultimate challenge for professional design.

\section{ACKNOWLEDGMENTS}

These reflections on design things are based on joint work developed with colleges Thomas Binder, Giorgio De Michelis, Giulio Jacucci, Per Linde and Ina Wagner. Between 2001 and 2004 we worked, together with other colleges, in a European research project on creative design environments, ATELIER. Since then we have jointly worked on a more comprehensive pragmatic and theoretical perspective on design practice and the things we design.

\section{REFERENCES}

1. Alexander, C., Ishikawa, S., Silverstein, M., Jacobson, M., Fiksdahl-King, I., Angel, S. 1977. A pattern language. Towns, buildings, construction. Oxford: Oxford, University Press.

2. Baker, K. Ribes, D. et al. 2005. Interoperability strategies scientific infrastructure:research and practice. American Society for Information Systems and Technology Proceedings, ASIST 2005.

3. Barry, A. Political Machines. Governing a technological society. London. Athlone.

4. Beyer, H., Holzblatt, K. 1998. Contextual Design. Defining Customer-Centered Systems. Morgan Kaufmann.

5. Borchers, J., Fincher, S., Griffiths, R., Pemberton, L., Siemon, E. 2001. Usability pattern language: Creating a community. AI \& Society 15(4):377-385.

6. Björgvinsson, E. 2007. Socio-material mediations. Learning, knowing and self-produced media within healthcare, Blekinge Institute of Technology.

7. Brown, B \& Perry, M. 2002. Of maps and guidebooks. Designing geographical technologies. DIS 2002.
8. Buur, J., Binder, T., \& Brandt, E. 2000. Taking video beyond 'hard data' in user centered design. Participatory design conference, 2000, New York.

9. Büscher, M. Christensen, M. Hansen, K. Mogensen, P. Shapiro, D. 2007. Bottom-up, top-down? Connecting software architecture design with use In Voß, A., Hartswood, M., Ho, K., Procter, R.; Rouncefield, M.; Slack, R.; Büscher, M. Configuring user-designer relations: Interdisciplinary perspectives. Springer Verlag.

10.Clark, B. 2007. Design as Sociopolitical Navigation. $\mathrm{PhD}$ thesis. University of Southern Denmark.

11. Cockburn, Alistair. 2002. Agile Software Development, Addison Wesley.

12. Crabtree, A. 2002. Pattern-based Support for Interactive Design in Domestic Settings. DIS 2002.

13. Dewey, J. 1927. The Public and its Problems. Holt, New York.

14.Edwards, K., Belotti, V. \& Newman, N.W. 2003. Stuck in The Middle. The Challenges of User-Centered Design and Evaluation of Infrastructure. CHI 03.

15.Ehn, P. 1988. Work-Oriented Design of Computer Artifacts. Arbetslivscentrum, Lawrence Erlbaum Associates, Hillsdale, NJ.

16.Ehn, P. \& Kyng, M. 1991. "Cardboard Computers" in Design at work: cooperative design of computer systems" eds Greenbaum, J. \& Kyng, M., Lawrence Erl $\neg$ baum Associates, Hillsdale, NJ.

17.Ehn, P \& Sjögren. 1991. From System Description to Script for Action in Design at work: cooperative design of computer systems" eds Greenbaum, J. \& Kyng, M., Lawrence Erlbaum Associates, Hillsdale, NJ.

18.Fensel, Dieter. 2003/2001. Ontologies: A Silver Bullet for Knowledge Management and Electronic Commerce - 2nd Edition. Berlin: Springer-Verlag.

19.Fischer, G. \& Scharff, E. 2000. Meta-Design-Design for Designers. In Proceedings of DIS 2000 pp. 396-405 ACM Press New York USA

20.Fischer, G. \& Giaccardi, E. 2005. Metadesign. A Framework for End-User Development in $\mathrm{H}$. Lieberman, F. Paternò, V. Wulf (eds.), End User Development. Empowering People to Flexibly Employ Advanced Information and Communication Technology, Dordrecht: Kluwer Academic Publisher, 2005.

21.Gaver, Bill, Tony Dunne \& Elena Pacenti. 1999. Cultural Probes. Interactions 6(1): 21 - 29.

22. Greenbaum, Joan \& Morten Kyng, eds. 1991. Design at Work: Cooperative Design of Computer Work. Hillsdale NJ: Lawrence Erlbaum Associates.

23. Haraway, D. 1991. Situated Knowledges: the science question in feminism and the privilege of partial 
perspective in D. Haraway (ed). Simians, Cyborgs, and Women. New York, Routledge.

24.Habraken, N. J., \& Gross, M. 1987. Concept design games (Book One: Developing, Book Two: Playing) (Report submitted to the National Science Foundation Engineering Directorate). Cambridge, Massachusetts: Department of Architecture, MIT.

25.Henderson, Kathryn. 1999. On Line and On Paper: Visual Representations, Visual Culture, and Computer Graphics in Design Engineering. Cambridge Mass: MIT Press.

26. Henderson, A. \& Kyng K. 1991. There is no place like home - continuing design in use. In J. Greenbaum \& M. Kyng (Eds.). Design at Work: Cooperative Design of Computer Systems, Lawrence Erlbaum, Hillsdale, New Jersey, pp. 219-240.

27.Jones, J C. 1984. Continuous Design and Redesign in Jones, JC, Essays in Design John Wiley and Sons New York USA.

28.Junk, R., \& Mü llet, N.R. 1981. Zukunjfrtwerkstätten Wege zur Wiederbelebung der Demokratie.

29. Krippendorf K. 1995. Redesigning design. In: Tahkokallio P and Vihma S (eds) Design Pleasure or Responsibility? University of Art and Design, Helsinki, Finland.

30. Koulamata 2005. The French Democracy. (http://movies.lionhead.com/movie/11520)

31.Krippendorf, K. 2006. The Semantic Turn. A new foundation for design. Taylor \& Francis Group, Boca Raton.

32.Lainer, R. and I. Wagner, 1998. Connecting Qualities of Social Use with Spatial Qualities in Proceedings of CoBuild98, eds. Streitz, N., S. Konomi, and H. Burkhardt, Springer, Heidelberg.

33. Latour B. 1999. Pandoras Hope, Essays on the Reality of Science Studies. Harvard University Press, Cambridge.

34.Latour, Bruno and Peter Weibel, eds. 2005. Making things public: Atmospheres of Democracy. Cambridge Mass: The MIT Press.

35.Lave, J. 1988. Cognition in practice mind, mathematics and culture in everyday life. Cambridge Univ. Press, Cambridge.

36.Lave, J., \& Wenger, E. 1991, Situated Learning Legitimate Peripheral Participaᄀtion, Cambridge University Press, Cambridge.

37.Leadbeater, C. 2007. We-Think. Profile Books, London.

38. Lowood, H. Found technology: Players as Innovators in the making of machinima. In: McPherson, T. (ed.) Digital Media and Learning. MIT Press, Cambridge (169-196).
39. Mau, B. and Leaonard, J. 2004. Massive Change. Phaidon.

40. McCullough, M. 2004 Digital ground: Architecture, pervasive computing and environmental knowing. Cambridge, Mass.: MIT Press.

41. Marres, N. 2005. "Issues Spark a Public into Being" in Latour and Weibel (eds.). Making Things Public, MIT Press, Cambridge.

42.Nardi, B A. 1993. A Small Matter of Programming. Perspectives on End User Computing. MIT Press, Massachusetts.

43. Norman, D. A., \& Draper, S. W. (Eds.) (1986). User centered system design: New perspectives on humancomputer interaction. Hillsdale, NJ: Lawrence Erlbaum.

44.Pedersen, J. 2007. Protocols of research and design. $\mathrm{PhD}$ thesis. IT Iniversity: Copenhagen.

45.Redström, Johan. 2008. Re:definitions of use. Design Studies.

46. Sanders, E. \& Dandavate, U. 1999. Designing for Experiencing: New Tools. Proceedings of the first international Conference on Design \& Emotion, Holland.

47.Star, Susan L. 1989. The Structure of Ill-Structured Solutions: Boundary Objects and Heterogeneous Distributed Problem Solving. In: Gasser, Les and Michael Huhns, eds. Distributed Artificial Intelligence Vol. 2. San Francisco Cal: Morgan Kaufman, 37-54.

48. Star, S. L. \& Ruhleder, K. 1997. Steps toward and an Ecology of infrastructure. Design and Access for Large Information Spaces. Information System Research.

49. Star, S,L. \& Bowker, X. 2002. How to Infrastructure. In L. A. Lievrouw, L.A. \& Livingstone, S.L. (eds.) The Handbook of New Media, London: SAGE, 151-162.

50. Suchman, L. 2000. 'Located Accountabilities in Technology Production', pub $\neg$ lished by the Centre for Science Studies, Lancaster University, Lancaster LA1 4YN, UK, at http://www.comp.lancs.ac.uk/sociology/papers/Suchma n-Locat $\neg$ d-Accountabilities.pdf

51.Tonkinwise, C. 2005. Is Design Finished? dematerialisation \& changing things In Willis, AM (Ed.) Design Philosophy Papers, Collection Two pp. 2030 Team D/E/S Publications Ravensbourne Australia

52.Tschumi B. 1994. Event Cities (Praxis), MIT Press, London.

53. Wenger, E. 1998. Communities of practice: learning, meaning, and identity. Cambridge University Press, Cambridge.

54. Wittgenstein, L. 1953. Philosophical Investigations. Basil Blackwell, Ox $\neg$ ford.

55.von Hippel, Eric. 2005. Democratizing Innovation, Cambridge, MA: MIT Press. 